

\title{
Chain-mail fabric stiffens under confining pressure Laurent Orgéas
}

\section{To cite this version:}

Laurent Orgéas. Chain-mail fabric stiffens under confining pressure. Nature, 2021, 596 (7871), pp.196197. 10.1038/d41586-021-02116-2 . hal-03320089

\section{HAL Id: hal-03320089 \\ https://hal.science/hal-03320089}

Submitted on 21 Oct 2021

HAL is a multi-disciplinary open access archive for the deposit and dissemination of scientific research documents, whether they are published or not. The documents may come from teaching and research institutions in France or abroad, or from public or private research centers.
L'archive ouverte pluridisciplinaire HAL, est destinée au dépôt et à la diffusion de documents scientifiques de niveau recherche, publiés ou non, émanant des établissements d'enseignement et de recherche français ou étrangers, des laboratoires publics ou privés. 


\title{
Chain-mail fabric stiffens under confining pressure
}

\author{
L. Orgéas \\ ${ }^{1}$ Univ. Grenoble Alpes, CNRS, Grenoble INP, 3SR Lab, F-38000 Grenoble, France \\ ${ }^{*}$ Corresponding author's email: laurent.orgeas@3sr-grenoble.fr
}

The mechanical properties of chain mail have been revisited. The findings reveal that, under confining pressure, chain-mail inspired materials can switch from pliable to stiff structures that have outstanding load-bearing capacities.



Figure 1. Increased contacts between particles alter the mechanical properties of a chainmail fabric under confining pressure. Wang et al. ${ }^{1}$ prepared a fabric that consists of layers of interlocked, 3D particles, inspired by chain mail. a: At low confining pressures (including ambient pressure), the particles in the fabric make relatively few contacts with each other, and the material is pliable. The number of contacts shown in the graphic are produced by a confining pressure of 2 kilopascals. b: At higher confining pressures (93 $\mathrm{kPa}$ in the graphic), the particles make a greater number of contacts with each other. The material becomes much stiffer and capable of bearing heavy loads, such as the 1.5-kilogram mass shown. Adapted from Figs 1 and 3 of ref. 1.

On page 238, Wang et al. ${ }^{1}$ report fabrics that consist of layers of interlocked, 3D particles a high-tech version of the chain-mail armour used by medieval knights. Under confining pressure, these materials undergo a phase transition known as a jamming transition. This 
profoundly alters their mechanical properties, transforming them from floppy textiles into rigid shells. These remarkable fabrics could be useful for applications in medicine and engineering. There is growing demand for materials that have properties optimized for a particular application, combinations of useful properties or even extraordinary properties not found in nature. The standard approach to achieving these goals is to modulate and refine the chemistry and nanostructure of materials, but this strategy sometimes has limits. A complementary approach ${ }^{2}$ is to design 'architected' materials, which have tailored topology and morphology at the mesoscale (which typically ranges from a few micrometres to a few millimetres), and can contain composite substructures. Related systems include: cellular materials ${ }^{3,4}$, such as foams and honeycomb structures; materials made from entangled fibres ${ }^{5}$ or interlocked subunits ${ }^{6}$; and materials whose mesoscale structures are active (they change behaviour in response to a stimulus) or programmable ${ }^{7-9}$.

Architected materials have attracted increasing interest over the past two decades, fuelled by advances in processes that can be used to manufacture mesoscale structures and, more recently, by the use of artificial intelligence (AI) and machine learning for materials design ${ }^{10}$. However, mesostructured materials are not new: paper and textiles are mesostructured, for instance.

Another historical example is chain-mail armour, which consists of interlocked metal rings. Chain mail was designed to have a high tensile strength and to protect the wearer from blows from weapons, but also to be pliable, so that it would drape and properly fit the human body. In fact, all material systems composed of discrete components, including chain mail and granular materials, exhibit a jamming transition ${ }^{11}$ under load that switches them from soft to stiff mechanics. But unlike granular systems, the jamming transition in chain mail can occur on bending or under tensile loading, because of the non-convex shape and interlocking of its structural elements.

Wang et al. have revisited the mechanics of chain mail, focusing on the jamming transition. They show that the tensile and bending properties of a chain-mail-inspired fabric can be radically and reversibly altered using con fining pressure as a driving force. The authors used 3D printing to fabricate chain mail from a polymer, in which each link is a hollow, 3D particle constructed from connecting struts (Fig. 1a). When the authors put the material into a flexible, sealed plastic bag and pumped out the air, the resulting confining pressure was large enough to trigger the chain mail's jamming transition - increasing the confining pressure from 0 to 93 kilopascals could increase the chain mail's stiffness by a factor of about 25 (Fig. 1b).

To understand the underlying mesoscale deformation mechanisms, Wang et al. carried out numerical simulations of various chain-mail architectures under tension or bending, at various confining pressures. The simulations showed that the experimentally observed stiffening is accompanied by a small reduction (less than $5 \%$ ) in the volume of the chain mail, which results in an increase in the number of contacts between the links in different chains (Fig. 1). Wang et al. show that contacts induced by the non-convex shape of the links and by link-interlocking have a central role in determining the efficiency of the jamming transition under tension and 
bending. Astonishingly, the authors also found that the increase of a chain mail's apparent bending modulus (which measures the stiffness of a material on bending) scales as a power law of the average number of contacts per chain-mail link, regardless of the simulated architecture

Wang and colleagues' chain mail presents intriguing opportunities for applications taking advantage of the fact that these pliable, lightweight, porous materials can easily be turned into rigid shells. A chain mail could conceivably be draped into multiple configurations before being jammed into a chosen static shape that has load-bearing capabilities, such as an exoskeleton for biomedical, sport or military applications. Chain mails could also be useful in civil or mechanical engineering as deployable structures (objects that can change shape in a way that greatly alters their size - for example, to create a temporary shelter or bridge).

There are some limitations to the current findings, which present stimulating challenges for future work. For instance, Wang et al. carried out experiments in which they measured how much a sample of the material flexes in response to an applied bending force at various confining pressures. They observed a linear relationship between force and flexure - that is, elastic behaviour - for small forces, and focused mainly on this elasticity in their analysis. But a non-linear relationship was observed for large forces, which became more pronounced at higher confining pressures. The mesoscale mechanisms responsible for this non-linear behaviour should be analysed further.



Moreover, there are numerous architectures of chain-mail links that could now be tested to explore their effect on the mechanical properties of chain mail. The use of AI algorithms ${ }^{10}$ might be an attractive approach to optimize the geometry of the links for targeted combinations of flexibility, jamming behaviour and load-bearing capabilities. It would also be interesting to switch from the conventional polymer used by Wang et al. to active materials, such as nanostructured thermoelastic polymers ${ }^{7}$ or shape-memory alloys ${ }^{5,9}$. The use of such materials might allow the stiffness of the chains in a chain mail to be tuned at different positions. Finally, it should be noted that the reported chain mails are essentially 2D structures; the mechanical properties of $3 \mathrm{D}$ versions of these materials now deserve investigation.

1. Wang, Y., Li, L., Hofmann, D., Andrade, J. E. \& Daraio, C. Nature 596, 238-243 (2021).

2. Ashby, M. F. Scripta Mater. 68, 4-7 (2013).

3. Bertoldi, K., Vitelli, V., Christensen, J. \& van Hecke, M. Nature Rev. Mater. 2, 17066 (2017).

4. Lakes, R. Science 235, 1038-1040 (1987).

5. Rodney, D., Gadot, B., Riu Martinez, O., Rolland du Roscoat, S. \& Orgéas, L. Nature Mater. 15, 72-77 (2016).

6. Dyskin, A. V., Estrin, Y., Kanel-Belov, A. J. \& Pasternak, E. Scripta Mater. 44, 2689-2694 (2001).

7. Haines, C. S. et al. Science 343, 868-872 (2014). 
8. Gladman, A. S., Matsumoto, E. A., Nuzzo, R. G., Mahadevan, L. \& Lewis, J. A. Nature Mater. 15, 413-418 (2016).

9. Gadot, B. et al. Acta Mater. 93, 311-323 (2015).

10. Mao, Y., He, Q. \& Zhao, X. Sci. Adv. 6, eaaz4169 (2020).

11. Liu, A. J. \& Nagel, S. R. Nature 396, 21-22 (1998).

The author declares no competing interests 